MENTAL

HEALTH LAW PROFILE

\title{
Mental health law in Saudi Arabia
}

\author{
Jessica Carlisle
}

Qualitative Research Fellow, Centre for Science, Knowledge and Belief in Society, Newman University, Birmingham, UK; University, Birmingham, UK;
email J.A.Carlisle@staff.newman. ac.uk

\section{Conflicts of interest. None.}

(c) The Author 2018. This is an Open Access article, distributed Open Access article, distributed
under the terms of the Creative under the terms of the
Commons Attribution-

NonCommercial-NoDerivatives

licence (http://creativecommons.

org/licenses/by-nc-nd/4.0/), which permits non-commercial re-use, distribution, and reproduction in any medium, provided the or any medium, provided the original work is unaltered and is properly cited. The written permission of Cambridge University Press must be obtained for commercial re-use or in order to create a derivative work.
During the past 30 years the Kingdom of Saudi Arabia has developed an extensive hospital-based mental health system culminating in the passing of a mental health law in 2014. This legislation embodies many of the international standards promoted by the World Health Organization. However, the mechanisms for protecting the human rights of psychiatric patients are neither sufficiently independent nor adequately robust.

Saudi Arabia is a high-income state in which oil wealth has funded improvements in health and education, resulting in it being ranked 39th of 187 states in the 2014 Human Development Index (Human Development Index and its Components; http:/hdr.undp.org/en/composite/ HDI; accessed November 2016). These improvements have included considerable expansion of its mental health system during the past 30 years and the passing of its first mental health law in 2014.

\section{Background}

The Kingdom of Saudi Arabia was established as an absolute monarchy in 1932, when King Abdulaziz was brought to power through military struggle and Islamic revivalism (Wahhabism). The state's constitutional document is the Basic Law of Governance (1992), which states that the government derives its authority from the Qur'an and the sunna of the Prophet and that these texts define all legislation (art 7). The king appoints, chairs and can dissolve the Council of Ministers (art 56 \& 57); supervises government ministries and agencies; and directs overall state policy (Council of Ministers Law 1993, art 29). The legislature consists of a 30-member Council of Ministers, headed by the King, and a 150member Shura Council containing committees of experts on matters including human rights, health and social affairs, security and Islamic affairs (art 3 \& 15, Shura Council Law 1992), which is appointed by the King. The monarch is additionally the head of the armed forces and appoints members of the judiciary (art $52 \& 60$, Basic Law of Governance, 1992).

The legislature is empowered to draft and adopt new law to address issues for which there is no explicit regulation in Islamic law (Royal Decree no. 19746, also art 67, Basic Law of
Governance, 1992). The courts apply a combination of Islamic shari' $a$ law and any legislation promulgated by the authorities that is not in conflict with the Qur'an and the sunna (art 48, Basic Law of Governance, 1992).

\section{Mental health system}

The Ministry of Health is the main provider of mental health services, with other government agencies providing psychiatric treatment for state employees. In the early 1980s, there were only two psychiatric hospitals in Saudi Arabia and psychiatric training was only possible up to a level of diploma (Koenig et al, 2014). In the late 1980s, Saudi physicians wishing to take up psychiatric consultant posts still had to do their postgraduate studies abroad. Almost all consultant psychiatrist and nursing staff were English-speaking non-Saudis. Psychiatric treatment was focused on medication, wards were locked and physical restraint was frequent (Al-Subaie, 1989).

From 1983, the Ministry of Health began to decentralise psychiatric services and established 21 regional psychiatric hospitals by 2014, which were augmented by free-standing private psychiatric clinics and psychiatric clinics based in many of Saudi Arabia's more than 125 private general hospitals (Koenig et al, 2014).

By 2006 a national mental health policy was in place that included specialty programs for those with addictions, children and adolescents, the elderly, and consultation-liaison services in general medical settings. However, hospitals remain the main specialist providers, with the result that many community mental health services are solely provided by primary care physicians (Koenig et al, 2014).

Mental health training is increasingly available to primary care doctors and postgraduates (Koenig et al, 2014). By 2010 there were over 700 psychiatrists and 1126 psychologists, social workers and occupational therapists working in mental health (Koenig et al, 2014). Senior staff members are increasingly Saudi nationals, although most nursing staff are still non-Saudis (Aldeham, 2009). This is relevant because the religion and culture of Saudi psychiatric patients should be taken into account during their treatment and the planning of mental health services (Koenig et al, 2014). There is evidence that mental health problems are underdiagnosed, with patients often presenting somatic symptoms (Becker, 2004) or understanding their experiences in religious terms (Alqahtani \& Salmon, 2008) and 
opting to seek treatment from traditional healers (Al-Habeeb, 2003).

\section{Legal reform}

The Saudi Arabian government has cooperated with the World Health Organization (WHO) in collating data about its mental health services and in developing policy (World Health Organization, 2013). Mental Health Law (2014) adopts many of the recommendations promoted by the WHO as contained in the United Nations Principles for the Protection of Persons with Mental Illness and the Improvement of Mental Health Care (1991) (MI Principles).

The legislation sets out clear definitions of mental illness and the qualifications required of professionals working in psychiatric care (art 1). Psychiatric facilities are instructed to maintain the standards established in the legislation and to document admissions and treatment (art 16). The law states that patients with capacity should be admitted voluntarily (art 10). There are limitations on the involuntary admissions, which are only justified on the grounds that the patient clearly presents a threat to themselves or others, and that treatment is "necessary for recovery, improvement or control of the deterioration of his condition' (art 13:1-2). The preferred option is for home treatment or in out-patient facilities (art 17:B). However, in emergency cases noncompliant patients can be admitted to a psychiatric facility for a maximum of 72 hours by a psychiatrist (art 11) and for 8 hours by a psychologist, social worker or psychiatric nurse (art 13). This can be extended (following review by a psychiatrist) for periods of 30,90 and 180 days (art 14), and then repeatedly (art 17:G). Two psychiatrists must prescribe involuntary treatment (art 17:E).

\section{Safeguards and human rights}

Psychiatric patients are awarded a raft of rights in the Mental Health Law (art 9). An interesting aspect of the legislative framing of rights is the recognition of the patient's kin in decision making about treatment, reflecting social norms about the importance of family input in medical care (Al-Mutair et al, 2014). Some of these rights adhere to WHO standards: rights to treatment in a safe and clean environment in accordance with 'commonly accepted and available standards' and to be protected from abusive or degrading treatment; to be fully informed about treatment and transfer between hospitals; to freedom of movement and visitors within the hospital; to confidentiality, the ability to file a complaint and to retain a lawyer; to refuse experimental treatment; to give or refuse their consent to treatment which both men and women can do from the age of 18 (Alosaimi et al, 2015) - if they are assessed as having capacity; and, if detained, to be held by the least restrictive means.

Patients and their relatives are also entitled to information about their rights and about involuntary detention and treatment (art 9:16-17). However, the law's standard for the involvement of involuntary patients in decisions about their treatment falls short of those promoted by the WHO. The commitment to patients' 'actual and continuing participation' if they are 'capable' (art 9:1) does not explicitly adhere to the WHO recommendation that 'despite the presence of a disorder that may affect capacity, a person may have the capacity to carry out some decision-making functions' (World Health Organization, 2005). In addition, guardians of patients can consent to experimental treatment on a patient's behalf (art 9:4). Moreover, the rights enshrined in Saudi Arabia's law do not specifically include the right to 'recognition everywhere as a person before the law' (MI Principle 13:1:a), access to facilities for recreation (MI Principle 13:2:a) and education (MI Principle $13: 2: \mathrm{b}$ ), and freedom of religion or belief (MI Principle 13:1:d).

Finally, the law's guarantee that a psychiatric patient can appoint a lawyer 'to defend their rights within and outside the mental health treatment facility' does not reach the international threshold of providing patients with access to costfree legal counsel to represent them in appeals (MI Principle 18:1), being able to participate in hearings in person (MI Principle 18:5), nor that they should be able to present 'independent' evidence and call witnesses (MI Principle 18:6) in support of their appeals.

The rights included in the Mental Health Act are augmented by the general Patient's Bill of Rights and Responsibilities (2006), which outlines more detailed rights for patients and their families including 'suitable education and rehabilitation methods for long stay [psychiatric] patients' and respect for a 'patient's cultural, psychological, spiritual and personal values, beliefs and preferences'. Research suggests that knowledge about their rights is poor amongst patients, who may not have read the information provided to them (Almalki et al, 2016).

\section{Mental health boards}

Before 2014, psychiatric services were supervised by a non-permanent 'human rights committee', which met to investigate reported problems in a hospital and to advise the government on mental health policies, legislation, service planning, monitoring and quality assessment (Qureshi et al, 2013). In 2014, only $40 \%$ of mental hospitals had had a review of their human rights protections for patients. The 2014 law established national and local supervisory boards (art $3 \& 6$ ) to supervise psychiatric care (including monitoring involuntary detention) and to consider grievances from patients, their families and their representatives (art $4 \& 7$ ).

Patients, their guardians or lawyers can appeal against involuntary treatment to the local boards (art 17:H-I), which can additionally allocate legal 
guardians to patients and authorise 'unorthodox treatments'.

Both the national and local boards consist of a combination of appointees from the Ministries of Justice, Interior, Health and Social Affairs, and hospital staff (psychiatrists, psychologists and social workers). The sole lay member on the national board is seconded from the national Human Rights Commission, a body fully appointed by the King (Council of Ministers Resolution 207/2005). The only lay member on each local board is 'a local citizen known for integrity' and is nominated by the national board. This falls short of establishing the degree of independence that WHO asserts is 'crucial' to the functioning of review bodies, which 'should not be influenced by political or departmental pressures or by health service providers' and should have a judicial or quasi-judicial structure when reviewing and monitoring involuntary detention and treatment orders (World Health Organization, 2005).

\section{Conclusion}

Saudi Arabia's mental health law is a step towards best medical practice and ensuring respect for the human rights of psychiatric patients. However, there is cause for concern because the legislation does not meet international standards regarding patient capacity and it fails to establish an independent review body. The onus on the courts to provide independent review, at least in part applying uncodified Islamic law, is an insufficient guarantee of patients' rights to appeal against involuntary detention or treatment.

\section{References}

Aldeham K. (2009) 'Needs Assessment of Users of Psychiatric Services in Saudi Arabia', PhD thesis, L. Douglas Wilder School of Government and Public Affairs, Virginia Commonwealth University.

Al-Habeeb T. A. (2003) A Pilot Study of Faith Healers' Views on Evil Eye, Jinn Possession, and Magic in the Kingdom of Saudi Arabia Journal of Family \& Community Medicine, 10, 31-38.

Almalki S. A., Alzahrany O. A. \& Alharthi H. A. (2016) Awareness of Patient Rights and Responsibilities among Patients Attending Outpatient Clinics, Taif Saudi Arabia. Merit Research Journal of Medicine and Medical Science, 4(1), 8-13.

Al-Mutair A., Plummer V. \& O'Brien A. P. (2014) Attitudes of Healthcare Providers towards Family Involvement and Presence in
Adult Critical Care Units in Saudi Arabia: A Qualitative Study. Journal of Clinical Nursing, 23(5-6), 744-55.

Alosaimi F. D., Altuwirqi M. A., Bukhari M., et al (2015) Psychiatric Disorders among Infertile Men and Women Attending Three Infertility Clinics in Riyadh, Saudi Arabia. Annals of Saudi Medicine, 35 (5), 359-67.

Alqahtani M. M. \& Salmon P. (2008) Cultural Influences in the Aetiological Beliefs of Saudi Arabian Primary Care Patients about Their Symptoms: The Association of Religious and Psychological Beliefs. Journal of Religion and Health, 47(3), 302-313.

Al-Subaie A. (1989) Psychiatry in Saudi Arabia: Cultural Perspectives. Transcultural Psychiatric Research Review, 26, 245-262.

Basic Law of Governance (1992) www.wipo.int/edocs/lexdocs/laws/ en/sa/sa016en (accessed August 2016).

Becker S. M. (2004) Detection of Somatization and Depression in Primary Care in Saudi Arabia. Social Psychiatry and Psychiatry Epidemiology, 39, 962-966.

Koenig H. G., Al Zaben F., Sehlo M. G., et al (2014) Mental Health Care in Saudi Arabia: Past, Present and Future. Open Journal of Psychiatry, 4, 113-130.

Law of the Council of Ministers (1993) https://www.boe.gov.sa/ ViewSystemDetails.aspx?lang $=$ en $\&$ SystemID $=6 \&$ VersionID $=11$ (accessed January 2018).

Mental health Law (2014) https://www.mindbank.info/item/5921 (accessed January 2018).

Patient's Bill of Rights and Responsibilities (2006) http://www.moh. gov.sa/en/HealthAwareness/EducationalContent/HealthTips/Pages/ Tips-2011-1-29-001.aspx (accessed November 2016).

Qureshi N. A., Al-Habeeb A. A. \& Koenig H. G. (2013) Mental Health System in Saudi Arabia: An Overview. Neuropsychiatric Disease and Treatment, 9, 1121-1135.

Shura Council Law (1992) https://www.saudiembassy.net/lawconsultative-council-majlis-al-shura (accessed January 2018).

United Nations Principles for the Protection of Persons with Mental Illness and the Improvement of Mental Health Care (1991) http:// www.un.org/documents/ga/res/46/a46r119.htm (accessed January 2018).

World Health Organization (2005) WHO Resource Book on Mental Health, Human Rights and Legislation. World Health Organization. Available at https://ec.europa.eu/health/sites/health/files/ mental_health/docs/who_resource_book_en.pdf (accessed August 2016).

World Health Organization (2013) Country Cooperation Strategy for WHO and Saudi Arabia 2012-2016. World Health Organization. Available at www.who.int/countryfocus/cooperation_strategy/ ccs_sau_en.pdf (accessed August 2016). 